\title{
Dioscorea villosa Tuber
}

National Cancer Institute

\section{Source}

National Cancer Institute. Dioscorea villosa Tuber. NCI Thesaurus. Code C71830.

An herbal remedy derived from the dried root of Dioscorea villosa, a perennial vine native to North America, Mexico and Asia. The root contains indigenous plant phytosterol estrogens such as diosgenin, which espouse therapeutic effects on female hormonal regulation and alleviate the symptoms of menopause, as well as induce antiproliferative pro-apoptotic effects in a diverse range of tumor cells. 